\title{
Deadly Disease vs. Chronic Illness: Competing Understandings of HIV in the HIV Non-Disclosure Debate
}

\author{
Erica Speakman \\ McMaster University, Canada \\ Dorothy Pawluch \\ McMaster University, Canada
}

DOI: https://doi.org/10.18778/1733-8077.17.4.02

\section{Keywords:}

HIV/AIDS; Non-

Disclosure;

Criminalization;

Constructionism;

Definitional Contests

\begin{abstract}
Over the past several decades, understandings of what it means to have contracted the human immunodeficiency virus (HIV) have shifted so that an infection once viewed as deadly and ultimately terminal is now largely regarded as chronic and manageable, at least in the West. Yet, the shift has not been complete. There are arenas of discourse where understandings of what health implications HIV carries with it are contested. One such space is the debate concerning the appropriate response to cases of HIV non-disclosure, that is, situations where individuals who are HIV-positive do not disclose their health status to intimate partners. This paper examines the competing constructions of HIV found within this debate, particularly as it has unfolded in Canada. Those who oppose the criminalization of non-disclosure tend to construct HIV as an infection that is chronic and manageable for those who have contracted it, not unlike diabetes. Those who support criminalization have mobilized a discourse that frames the infection as harmful and deadly. We use the case of the HIV non-disclosure debate to make the argument that representations of health conditions can become mired in larger social problems debates in ways that lead to contests over how to understand the fundamental nature of those conditions.
\end{abstract}

Erica Speakman currently teaches in the Sociology Department and Social Psychology Program at McMaster University. Broadly speaking, her research interests include the study of deviance, crime, and social problems, as well as the sociology of health and illness. Specifically, her research is concerned with how illness, criminal law, and social problems intersect.

email address: hiltze@mcmaster.ca
Dorothy Pawluch recently retired after a career that spanned over 30 years in the Department of Sociology at McMaster University and included the development of the Social Psychology Program at the university. Her interests include social constructionism, social problems, deviance, and medical sociology.

email address: pawluch@mcmaster.ca 


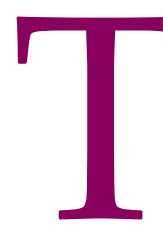

here has been an ever-growing appreciation within the social sciences that disease is not something that is objectively given, but a construction subject to the interpretative work of social actors as they engage in the meaning-making activity (Conrad and Barker 2010; Pawluch 2016). As a result of this interpretative work, behaviors, conditions, and states of being once considered "normal" come to be seen as events that call for medical intervention. This development has been well documented, for example, in connection with childbirth (Oakley 1984), infertility (Scritchfield 2009; Bell 2016), premenstrual syndrome (Figert 1996), menopause (McCrea 1983), erectile dysfunction and andropause (Conrad 2007), weight (Sobal and Maurer 1999), shyness (Scott 2006), dementia (Harding and Palfrey 1997), and even death and dying (Horwath 2007). In other cases, behaviors that are now viewed as symptomatic of disease were once seen as lapses in moral judgment or deviant behaviors (Conrad and Schneider 1992; Conrad 2007). These definitional shifts, as social accomplishments, have been studied in connection with mental illness (Szasz 1961), hyperactivity or ADHD in children (Conrad 2007), child abuse syndrome (Pfohl 1977), and sexual compulsivity (Levine and Troiden 1988), to name just a few.

The process of medicalization can also work in reverse. Just as diseases are constituted as identifiable and objective entities through interpretive social processes, through those same processes they can be reconstituted as something other than disease. Homosexuality was once considered a psychiatric disorder and listed in the Diagnostic and Statistical Manual, but has now been normalized (Spector 1977; Conrad and Angell 2004). Late $19^{\text {th }}$ century views of masturbation as a disease were supplanted in the $20^{\text {th }}$ century with understandings of masturbation as a normal part of human sexual development (Conrad and Schneider 1992). "Paraphilia" - a catchall diagnosis for BDSM (an acronym for a variety of sexual practices that include bondage, dominance, submission, and sadomasochism) is undergoing a similar definitional shift as advocates press a rhetoric of freedom of sexual expression (Lin 2017).

Citing the contributions of sociologists of medicine like Freidson (1970), Waitzkin (1989), and Zola (1972), as well as developments in the sociology of science, Brown (1995) has drawn attention to the importance of acknowledging the social forces and interactive meaning-making processes involved in shaping what we make of health and illness. Brown's (1995:38) notion of a "sociology of diagnosis" treats medical categories and diagnoses as instances of the "politics of definition" and focuses on exploring processes of "naming and framing" (Brown 1995:35). Brown offers a typology of conditions, including conditions around which there is consensus so that the condition is universally accepted as a disease and others where groups are still seeking to have disease labels applied or recognized as legitimate in an environment where others might be contesting the "disease" status of the condition.

We situate our analysis within these conceptual debates. However, our paper is concerned not so much with contests over whether a condition ought to be viewed in medical terms, but about the fundamental nature of a condition and what kind of medical threat it represents. Competing constructions of HIV-HIV as a deadly and life-threatening virus versus HIV as a chronic and manageable virusare examined. When first discovered in the 1980s, HIV was generally understood to be an infection with life-threatening implications. The prognosis for anyone receiving an HIV-positive diagnosis was 
dire, carrying with it the expectation of an inevitable progression into AIDS, a shortened lifespan, and death, often within mere months (Beaudin and Chambre 1996). Even in the earliest days of the epidemic, there were segments of the HIV community who resisted the fatalism in this prognosis. For example, Gamson (1989) and Gillett (2011) have written about the refusal on the part of many people living with HIV to believe that their diagnosis was a hopeless death sentence. By and large, however, the virus generated a great deal of fear and uncertainty, particularly among groups believed to be most at risk of infection-gay men, intravenous drug users, and sex workers (Herek and Glunt 1988).

The campaign to redefine HIV from an ultimately life-threatening virus to a virus that could be managed gained traction, at least in the West, in the early 2000s. The shift was prompted in part by an increased understanding of HIV and related disease processes and the development of treatments. The antiretroviral therapies (ART) that were developed in the late 1980s showed signs of being successful in at least slowing down the virus. By the mid-1990s, ART had started to give way to highly active antiretroviral therapies (HAART), which were even more effective and afforded those infected with HIV the opportunity to reach near-normal life expectancy and prolonged, disease-free health (Samji et al. 2013; Webel 2015).

As Beaudin and Chambre (1996) argue, non-medical factors also contributed to the shift. They point to the role played by the formal and informal organizations and communication channels set up by the AIDS community, made up then largely of gay white men. The community agitated for a dramatic expansion in the services and programs available for people living with HIV/AIDS (PHAs). Gradual- ly, the short-term and crisis-oriented responses that characterized HIV's early history were replaced by a greater appreciation for the long-term needs of a diverse population of people living with a complex and uncertain combination of chronic and episodic needs. Advances in treatment have continued, with the latest research focused on the use of bone marrow transplants to induce remission (Canadian AIDS Treatment Information Exchange 2021). With each advance, the framing of HIV/AIDS as a manageable condition is reinforced. But, again, we emphasize that these developments pertain largely to Western countries. In much of the developing world, access to therapy is limited, and HIV continues to be regarded as a significant public health burden (Chan 2017; UNAIDS 2021; WHO 2021).

Yet, even in the West, there are arenas of both expert and popular discourse where questions about the threat of HIV persist and where a view of HIV/ AIDS as deadly can still be found. One such arena is the debate surrounding the criminalization of HIV non-disclosure. As our analysis will show, those who oppose criminal sanctions against individuals who do not disclose their HIV-positive status (referred to from here on in as non-disclosers) build their claims on an understanding of HIV as a chronic and manageable infection. On the other hand, those who favor the criminalization of non-disclosers as an effective method for stopping the spread of HIV are more likely to promote a view of HIV as deadly and a diagnosis of infection as devastating.

Our concern in this paper is to examine the competing claims made about HIV-a "life-threatening and deadly" view of the virus versus a "chronic and manageable" view. We want to make clear that we are not addressing the issue of what sort of con- 
dition HIV/AIDS really represents. Our analysis is not intended to challenge or endorse any specific view of HIV/AIDS. We position ourselves decidedly on the sidelines of the debate for reasons we elaborate in our discussion of the theoretical perspective that informs our analysis. We start our paper by providing a brief background into the issue of HIV non-disclosure and the debate about how non-disclosers should be treated. Then we turn to the perspective that informed our analysis. After briefly describing the methods we used, we discuss the typifications of HIV inherent in the claims made by both those who favor criminalization and those who oppose it. The paper concludes with a discussion of a series of more general questions about the links between disease construction and social problems claims-making. We argue that definitions of health conditions can become mired in larger social problems debates in ways that lead to contests over how best to understand the fundamental nature of health conditions.

\section{The Criminalization Debate}

Among the challenges that HIV has presented is the issue of how to deal with non-disclosers or those who do not disclose their HIV-positive status to those with whom they are intimate. Like much of the Western world, Canada initially showed a preference for public health rather than a criminal approach. While a criminal response involves the laying of criminal charges-typically sexual assault charges-against non-disclosers, a public health approach emphasizes education. The recently diagnosed are targeted, informed about the risks involved with having unprotected sex and their legal obligations to disclose their positive status to any potential sexual partner. In cases where non-disclosers are reported to public health authorities, be- havior orders or warnings may be issued. Only as a last resort would public health officials contact the police.

However, since the early 2000s, both in Canada and elsewhere, there has been a move in the direction of criminalization, with a dramatic increase in the use of criminal sanctions (French 2015). Mykhalovskiy (2015:373) notes that, as of 2010, approximately "41 countries had prosecuted people living with HIV for non-disclosure, exposure, and transmission." In Canada, between 1989 and 2009, 98 individuals were criminally charged for not disclosing their HIV-positive status to their sexual partners. However, approximately 68 percent of all prosecutions for non-disclosure occurred in the five years between 2004-2009 (Mykhalovskiy, Betteridge, and McLay 2010). Since there are no HIV-specific criminal laws on the books in Canada, the charge typically used is "aggravated sexual assault." In the United States, since 2003, it is estimated that there have been approximately 541 HIV-related offense convictions in 19 states (Hernandez 2013 as cited in Mykhalovskiy 2015). Hoppe (2014) argues that in the United States, 33 states have enacted criminal sanctions against those who are HIV-positive, a phenomenon he refers to as the "criminalization of sickness."

The trend towards criminalization has generated debate and controversy. Many policymakers and public health authorities, academics, human rights activists, people living with HIV/AIDS, and AIDS service organizations have taken the position that criminalization is an inappropriate response and counter-productive to the goal of combating the spread of HIV/AIDS. Arguments against criminalization include observations that criminalization deters individuals from getting tested, erodes pub- 
lic health norms of mutual responsibility, and exacerbates the stigma attached to HIV, all of which puts the general population at greater risk, not less. Opponents of a criminal approach point to the historical record of failed attempts to control sexual activity using criminal law, ambiguities in the law concerning the conditions under which individuals are required to disclose, and the potential for criminal laws to be applied in discriminatory ways. They also point to the therapies that have significantly reduced, if not eliminated, the risk of HIV transmission (Galletly and Pinkerton 2006; Jürgens et al. 2009; Merminod 2009; Mykhalovskiy et al. 2010; O'Bryne, Bryan, and Roy 2013; French 2015; Swiffen 2015). Adam (2006; 2015; Adam et al. 2013) has argued that criminalization as a strategy for preventing transmission will not work simply because of the gap between "the practicalities of disclosure in everyday life and the somewhat abstracted vision of the rational actor envisioned in court decisions requiring near-universal disclosure in sexual interactions" (Adam et al. 2015:386).

Pro-criminalization arguments stress the rights of those potentially at risk because of non-disclosers. Non-disclosure denies individuals access to vital information they need before engaging in sex. This matters because infection with HIV is at stake. Apart from the health consequences connected to HIV infection, there are serious social consequences. HIV continues to be highly stigmatized, and the lives of those who become infected are significantly compromised. They experience status loss, discrimination, and isolation. Given the gravity of the potential health and social consequences, a tougher approach is warranted (Elliott 1999; Lazzarini, Bray, and Burris 2002; Merminod 2009). Lazzarini and colleagues (2002:329) summarize the legal rationale for criminalization in this way:
It may deter unsafe behavior by the threat of punishment; it may help convince people with HIV that risky behavior is wrong, by supporting a social norm against the behavior; or it may incapacitate through imprisonment those who have a propensity toward unsafe behavior.

There is evidence to suggest that some service providers and PHAs themselves support this position. For example, Lichtenstein, Whetten, and Rubenstein (2013) found that $90 \%$ of the HIV providers in North Carolina supported disclosure laws with criminal sanctions for non-disclosers. In addition, a review of the extant literature on this question ( $\mathrm{O}^{\prime}$ Byrne et al. 2013) showed that while qualitative studies among PHAs indicate opposition to criminalization, quantitative, survey-based studies generally show support for HIV criminal laws. Adam and colleagues (2013) found support for the prosecution of the high-profile non-disclosure cases among PHAs, though participants also expressed concerns about the degree to which those who are criminally charged are presumed to be guilty until proven innocent and, therefore, carry the burden of proof when it comes to establishing their innocence. In a study of young men in the Vancouver area who were HIV-seronegative, or did not know their HIV status, Knight and colleagues (2018) found that a significant number felt a criminal approach was justified.

While the debate around criminalization is interesting and important, our concern in this paper is not with appropriate responses to non-disclosure. Rather, we are interested in the divergent constructions of HIV contained within the arguments that each side advances in defense of its position. Before describing the data we analyzed to address this issue, we discuss the framework that informs the questions we are asking. 


\section{A Social Constructionist Perspective}

In exploring the issue of competing constructions of HIV in the criminalization debate, we bring a social constructionist perspective to bear on our analysis of the data. Broadly speaking, social constructionism is concerned with how social actors create meaning, make sense of their worlds, and construct reality (Berger and Luckmann 1967; Hacking 2000). The perspective has pushed many areas of scholarly inquiry in the direction of looking at subjectivities as constitutive of reality. We started our paper by covering some of the literature that the constructionist perspective has generated in the sociology of health, where the focus has been on how understandings of conditions as disease emerge and change. While much of that literature was being produced, there were parallel developments in the sociology of social problems. In 1977, Spector and Kitsuse published Constructing Social Problems, a book that took issue with the focus in the sociology of social problems on objective conditions (poverty, family violence, crime, etc.). Insisting that conditions become problematic only by virtue of the subjective judgments that individuals make with respect to these conditions, they urged sociologists to stop studying social problems as objective facts and to consider instead how certain conditions come to be $d e-$ fined as problematic. Since social problems are a matter of social definition, and these definitions change over time, they insisted that the emphasis should be on the social processes by which these definitions come about and the claims-making activities that generate them.

Building on the agenda that Spector and Kitsuse laid out for sociologists of social problems, Loseke (2003a) elaborated on the three interconnected elements involved in the social problems claims-making process-the construction of conditions (diagnostic framing), the construction of people (motivational framing), and the construction of solutions (prognostic framing). Diagnostic frames essentially communicate to audiences why a particular condition is problematic; motivational frames focus on the individuals connected with the condition as either victims or villains, thereby providing audiences with a rationale for caring about the issue; and prognostic frames suggest what needs to be done to ameliorate the condition.

Elsewhere, Speakman (2017) has used the concept of motivational framing to look at how non-disclosers are characterized in the criminalization debate, finding that proponents of criminalization are more likely to construct non-disclosers as villains while opponents construct them as victims. In this paper, we look more at the diagnostic and prognostic framing going on in the debate. How conditions are framed, Loseke (2003a) points out, is often related to the solution that is ultimately proposed, linking diagnostic and prognostic frames in decisive ways. To illustrate, she uses the example of "transportation for disabled people." If the condition is framed simply as a problem with transportation itself, the solution is to call for more funding for adequate transportation. On the other hand, the framing of the problem as a violation of civil rights would call for looking beyond transportation issues at the broader institutionalized discrimination against those who are disabled.

Loseke (2003a) also notes that in some cases, the definition of the condition itself can become a point of contention between claims-makers and counter claims-makers. That is, there may be agreement about the existence of the condition, and perhaps even on the issue of whether the condition is problematic, but not on how to typify or characterize the condition. The debate around the criminalization of HIV non-disclosure offers a unique opportunity to explore the issues that Loseke raises, particular- 
ly around how competing definitions of a condition (HIV infection) are linked to competing definitions of the appropriate solution (education or criminalization of non-disclosers).

There will be readers unsettled by the fact that our analysis resists privileging any particular view over another. This includes the views of HIV researchers and medical experts. We put those views on the same ontological plain as the views of non-experts and members of the general public who have weighed in on the criminalization debate. In doing so, we want to make clear that we are not challenging the science around HIV/AIDS. Our point is simply that how HIV should be viewed is still contested territory. We recognize that which view prevails has serious consequences, not only in terms of how we deal with non-disclosers but more broadly on how much of a priority HIV/AIDS becomes in national health policies and in the funds it receives for research, treatment, and services (Scandlyn 2000). However, we also recognize that which view prevails will be determined not by us, but in the "social problems marketplace" (Best 2015) within which claims-makers and their audiences operate and where "truth" claims are ultimately arbitrated. That makes it all the more important to understand how these contests are fought and won. Hence our interest in how claims are framed and how respective positions are advanced, without regard to questions about the validity or truth value of claims (for more on this issue, see: Pawluch 2019).

\section{Method}

\section{Qualitative Data Analysis}

The data for this study came primarily from internet sources and were analyzed using qualitative docu- mentary analysis. There are specialized varieties of documentary analysis, such as archival and historical research (Gidley 2017) and the qualitative media analysis approach developed by Altheide and Schneider (2013) specifically for examining traditional print media (e.g., newspapers and magazines and more recent forms such as television broadcasts and cyberspace). But, in its more generic form, qualitative documentary analysis refers to the systematic examination of any type of document to "elicit meaning, gain understanding, and develop empirical knowledge" (Bowen 2009:27). The term "documents" has gradually expanded to take in an ever-wider range of materials-written, printed, oral, recorded, photographed, painted, and virtual (Tight 2019). Among the advantages of working with this type of data, according to Lincoln (1980:10), is the fact that documents represent a "natural" source of information-"a delight to the naturalistic inquirer." They are an "in context" source of information in that they are generated in the context of everyday interaction, not elicited by the researcher. Moreover, they provide information about the context, in the sense that they provide a record of the environment as social actors define it. Lincoln (1980:10) concludes: "They are repositories, as a result, of some of the best grounded data available on the events or situations under investigation."

\section{The Johnson Aziga Case}

For this study, we worked with agency reports, academic papers, press releases, news stories, editorials, letters to the editor, comment feeds, blogs, and chat rooms. A strategy that proved useful in locating many of these documents was to start with a particularly high-profile case in Canada-the case of Johnson Aziga-and then to carefully track as much of the coverage and commentary as was 
accessible. Since many of the quotes refer to the Aziga case, we provide a summary here. Johnson Aziga was a Ugandan-born immigrant to Canada whose non-disclosure of HIV-positive status led in 2009 to a conviction of two counts on first-degree murder, ten counts of aggravated sexual assault, and one count of attempted aggravated sexual assault. In 2011, the prosecution petitioned the court to declare Aziga a dangerous offender, a designation usually reserved in Canada for only the most heinous criminal offenders. The court granted the request, meaning that Aziga's incarceration is indeterminate and that his sentence is likely to be lifelong.

Aziga was not the only criminal non-disclosure case to generate media attention in Canada (for a comprehensive media analysis of all HIV criminalization cases covered in Canadian English-language newspapers between 1989 and 2015, see: Mykhalovskiy et al. 2016). But the Aziga case does stand out, most notably because it was the first time a first-degree murder conviction had been handed down in connection with HIV non-disclosure. That may be why the case prompted such intense debate, at least in Canada.

\section{Data Collection and Analysis}

An online search using Aziga's name generated a multitude of hits. While many of these documents were trial-related and included summaries of the trial itself, related hearings and appeals, and victim impact statements, others were reactions to and commentaries about non-disclosure generally. In addition, we used the LexisNexis database to locate all articles in Canadian news sources between 2003-2014 that referred to "Aziga"-approximately 350 in all.
We did not limit ourselves to Aziga-related material. The Aziga case was simply our entry point into larger discussions about non-disclosure. When we found those entry points, we tracked the discussions in a snowball fashion wherever they led. That road took us to a broad range of websites, some of which were entirely unrelated to Aziga or even HIV for that matter. For example, among the sites that included comments about HIV non-disclosure were PlentyOfFish.com, a free dating website, and Queerty, gay and lesbian news and entertainment site. After eliminating articles that were re-posts from other sites, we were left with 92 documents as the basis for our analysis. The documents ranged in size from one-page notes to the 87 pages of comments following an article published on Slate.com.

Given the range of sources, it is not surprising that there was a great deal of variability in the data as far as style, tone, and technical sophistication. While reporters on news and organizational sites typically identified themselves, those who contributed to comment feeds typically used a pseudonym or wrote anonymously. Some contributors wrote as interested parties (people living with HIV, clinicians, lawyers); others appeared to simply be members of the public with an opinion on these matters. In some cases, the comments were detailed and more formal in tone. In other cases, they were brief and written casually, sometimes using profanities and negative stereotypes. In some cases, views were expressed using temperate, civil language; in other cases, in extreme and offensive terms. The latter was especially true for those who supported criminalization and wrote anonymously. Anonymity allows individuals to express themselves in unrestrained ways since they cannot be held accountable for what they say (Kling et al. 1999). Since we intended to get a sense of how HIV 
was constructed in the discourse around the issue of non-disclosure, irrespective of where those conversations were happening and the language used, we included all the data collected. That also meant that we did not make distinctions between contributors to the discourse in terms of their status or credibility. As we explained earlier, we were aiming to identify competing constructions of HIV, not to judge those constructions based on who generated them.

Regarding our analytical process, the goal in the qualitative documentary analysis is to immerse oneself in the text and to produce thick or detailed accounts of one's findings (Berg 2006). This paper originated in a related analysis about how non-disclosers were represented in the criminalization debate (Speakman 2017), depending on whether they favored or opposed criminalization. However, that analysis showed that contributors spoke differently not only about non-disclosers (as victims versus villains) but also about HIV itself. Once HIV emerged as a focus, the data were subjected to a careful coding process that involved looking at any reference to HIV and exploring how the virus was represented in that content. Themes were then identified in these typifications, which ultimately became the basis for the analysis that follows. We drew the terms "deadly" and "manageable" directly from the competing discourses about HIV.

\section{Caveats}

We conclude this section with several caveats. First, it is not at all clear how representative the data we collected are of the full range of views around the criminalization of non-disclosure. People tend to react publicly only when they have a vested inter- est in the issue being debated or feel strongly about the issue. Therefore, our data may have captured both ends of the continuum and less of the more moderate views in between, giving the impression of a debate more polarized than is the case.

Second, our data do not capture the prevalence of the competing points of view on criminalization or how pronounced each was in relation to the other. Mykhalovskiy and colleagues (2016:12-13) argue that public understandings of crime in general, and the HIV criminalization debate more specifically, are shaped by how the mainstream media presents these issues. Their analysis of media representations of HIV non-disclosure cases-including the Aziga case-in the Canadian, English-language media showed that coverage focused disproportionately on African, Caribbean, and Black defendants and paid an inordinate amount of attention to their immigration status. The sensationalized coverage, they suggest, has informed how people think about and respond to HIV non-disclosure. The counter-discourses offered by AIDS service organizations, networks of people living with HIV, and the scholarly and alternative press have received "limited reach." They may be right, but to what extent either discourse holds sway, and among which audience is an empirical question that has yet to be answered.

Third, we were not able to capture temporal dimensions of the debate and how significantly positions shifted as new therapies for HIV/AIDS emerged or new policies were rolled out. What we can say is that throughout the period covered by the data, including the most recent data, there were vociferous voices on both sides of the debate. It was those voices, and how they constructed HIV as a disease, that most interested us. 


\section{HIV as a Chronic and Manageable Virus}

We outlined earlier the range of arguments that those opposed to the criminalization of HIV non-disclosure have marshaled in making their case, including the point that criminalization undermines HIV counseling, educational, and preventative efforts in a way that increases rather than reduces risks to the general population. Their anti-criminalization position did not rest entirely, or even principally, on their construction of HIV as a manageable virus. However, that construction does enter the discourse in connection with the argument about advances in science and the disjuncture that has created between the severity of the response (criminal charges) and the nature of the threat (risk of HIV infection). To be fair, the risk of infection is different from the nature of the infection. We appreciate that saying that the risk of infection has become minimal is not the same thing as saying that the infection itself represents a minimal threat. But, as we show below, in much of the anti-criminalization discourse, the nature of the infection did become part of the discussion. In that discussion, HIV was constructed as chronic and manageable.

Opponents often referred to advances in treatment and new knowledge not (or not only) as it affects the risk level, but in terms of how it mitigates the effects of living with HIV on a long-term basis. Based on this new knowledge, opponents argued, the dire prognosis that was once common for those diagnosed as HIV-positive has been greatly reduced, and the probability of living a full and normal lifespan greatly increased. This argument is reflected in a comment made following a Globe and Mail editorial.

BTW-HIV/AIDS is no longer a death sentence in this country [Canada]. Proper drugs and lifestyle can have those living long productive lives. [Globe and Mail 2010]

In a report critical of the trend towards criminalization in Canada (Mykhalovskiy et al. 2010), the authors underline the dramatic medical advances that have taken place since the first precedent-setting cases were tried and insist that the law has simply not kept up with the science around HIV. The report argued that this gap may be partly a result of the "complex and rapidly evolving nature of scientific research on HIV sexual transmission risks" (Mykhalovskiy et al. 2010:26). But, beyond addressing the question of risk, the report also characterized HIV as a "chronic and manageable condition," akin to diabetes:

With the advent of effective therapy in the mid-1990s, life expectancy for people living with HIV has steadily increased. The World Health Organization and other leading health authorities consider that, with proper medical care, HIV is a chronic manageable condition, similar in many ways to other chronic conditions such as diabetes or cardiovascular disease. [Mykhalovskiy et al. 2010:26]

A similar argument is made in a comment thread on Queerty discussing criminal charges laid against an HIV-positive gay man:

Why is it, well over a decade after HIV disease became a non-instant death sentence, that Canadian authorities are beginning to pull crap like this? [Queerty 2010]

A health editor for the Globe and Mail goes even further in the claims made for the effectiveness of current treatments, suggesting that treatments have made it possible to reduce the level of the virus in the system to a virtually undetectable level: 
At the beginning of the AIDS epidemic, doctors had little means of treating the disease, and most patients faced certain death. But, medical advances transformed HIV treatment. Patients given highly active antiretroviral therapy, known as HAART, can now expect to live an almost normal lifespan. Furthermore, the drugs reduce HIV to undetectable levels in semen, vaginal fluids, and blood. [Taylor 2011]

The reference to the undetectability of the virus is significant in that it reflects the position that a number of HIV experts, including scientists, advocates, and organizations, have taken in the last few years. Captured in a slogan first promoted by the Prevention Access Campaign, a multi-agency health equity initiative launched in the US in 2016 (Prevention Access Campaign 2016), “Undetectable equals Untransmittable" (or $\mathrm{U}=\mathrm{U}$ ) rests on the premise that HIV-positive individuals showing undetectable viral loads of HIV-200 copies/ml or less-for at least six months represent no infection risk to their partners at all.

Since its inception, the $\mathrm{U}=\mathrm{U}$ movement has been aggressively promoting the notion that individuals with undetectable viral loads should be under no moral obligation to disclose their HIV-positive status to their sexual partners. In terms of the criminalization debate, the implication of the $\mathrm{U}=\mathrm{U}$ campaign is that individuals cannot be held criminally responsible for an action (non-disclosure) that is within their rights. The $\mathrm{U}=\mathrm{U}$ campaign reinforces the argument that in cases of HIV non-disclosure, the law has simply not kept pace with science. Those who oppose criminalization juxtapose accounts of advances in HIV treatment and their effect on reducing the threat of death once linked to HIV against the trend towards greater criminalization. They point to the irony in the fact that as HIV becomes more manageable, criminal charges have increased in number.
A contributor to the dailyxtra.com news site pointed to a consensus statement issued by a panel of HIV experts that takes a similar position:

Just last month, dozens of Canadian scientific experts released a consensus statement that said, "A poor appreciation of the science related to HIV contributes to an overly broad use of the criminal law against individuals living with HIV in cases of HIV non-disclosure...We are concerned that actors in the criminal justice system have not always correctly interpreted the medical and scientific evidence regarding the possibility of HIV transmission, and may not have understood that HIV infection is a chronic and manageable condition. This may lead to miscarriages of justice." [Fouchard 2014]

The view of HIV as a chronic, manageable condition comes through as well in another argument that opponents of criminalization make, having to do with the precise charges laid in non-disclosure cases. While opponents take exception to any use of the law in non-disclosure cases, they are particularly against the use of criminal law, claiming that criminal charges do not align fairly with the severity of the harm caused. In one case in the United States, an HIV-positive person was charged with bio-terrorism for allegedly biting a neighbor during an altercation. In commenting on this case, a reporter at one news outlet wrote:

...the wealth of research on HIV/AIDS over the last three decades contrasts sharply with ongoing public misconceptions that are codified by policies that criminalize disease-paving the way for [people living with HIV] to find themselves susceptible to terror charges for actions that not only are demonstrably incapable of spreading HIV but would, for a non-HIV positive person, carry much less serious sanctions. [Alternet.org 2010] 
Even those who would like to see some sort of consequence for non-disclosure take the position thatgiven the nature of the virus - a more appropriate response would be a fine or a public health warning. The proposed response is a measure of the seriousness of the offense from the perspective of those who do not see HIV as life-threatening. That is to say, as a manageable condition, HIV does not warrant the kind of response that might be justified if it were, in fact, a death sentence. The ridiculing of current responses, juxtaposed against actions typically understood as examples of bioterrorism, serves to indirectly challenge a view of HIV as deadly and threatening.

\section{HIV as a Deadly Disease}

Arguments on the pro-criminalization side of the debate are similarly multi-faceted and complex. However, those arguments too rest on a particular understanding of what it means to be infected with HIV. The assumptions that some proponents leave implicit in their arguments in favor of criminalization are expressed by others in explicit terms. For example, HIV is characterized as a "killer virus." The actions of non-disclosers are described as "basically attempted murder" (Positive Living BC 2014), and the virus they harbor as a "murder weapon" (Clairmont 2011). Characterized in this way, criminalization of non-disclosure is seen as warranted. The gravity of the wrongs perpetrated against those who become infected as a consequence of their relationships with non-disclosers justifies the severity of the response to non-disclosure. As one proponent of criminalization put it:

The fact is, they put their partners in tremendous danger by not disclosing their status. The law is reasonable and moral. [Positive Living BC 2014]
A contributor to the same comment thread draws an analogy between non-disclosure and drunk driving, emphasizing the deadly nature of HIV in the process:

If I drive home drunk, and [no one] gets hurt, I can still go to jail for a DUI. Attempted murder is a stretch, but HIV is a life-changing, potentially fatal illness, and someone who doesn't respect their partner enough to inform them should be punished. [Positive Living BC 2014]

"Harm" in much of this rhetoric extends beyond those who are infected by a non-discloser to instances where a partner has to live with the uncertainty and anxiety of not knowing if their test results will come back positive for HIV. In the case of Johnson Aziga, some of the women who were exposed did not contract HIV, but the psychological harm that they suffered before their test results came in was emphasized. Victims were described as being traumatized. News accounts referred to a woman who had decided with her current partner that if her test results came back positive, they would carry through on a suicide pact they had made. She is said to have described the waiting as "pure torture" (Nguyen 2011). In one comment thread on AlterNet.org, non-disclosure was equated with terrorism:

If you have HIV and you bite someone, then YOU ARE A TERRORIST. A biological terrorist. Period. [Alternet.org 2010]

The magnitude of the offense was also underlined in the kinds of penalties supporters of criminalization see as appropriate. News coverage of another non-disclosure case-the case of Vincent Walkemelicited several responses. Walkem was found guilty 
and sentenced to 56 months in jail. One contributor to the discussion thread wrote:

I say keep him locked up, as a menace to society, and take away his drugs. Let him rot to death, carry out the death sentence he so willingly handed out. [Plenty of Fish 2007]

Another contributor called for the re-institution of the death penalty for such cases (capital punishment was abolished in Canada in 1976). Others recommended castration and physical branding:

Not only should it [HIV non-disclosure] remain a crime but castration should be the punishment. [Plenty of Fish 2007]

Since this guy has shown a willingness to expose others without telling them... Tattoo "HIV Infected" in inch-high letters right across his face. [Plenty of Fish 2007]

The extreme nature of the descriptors used and sanctions called for in these instances have the effect of underlying the gravity of the harm caused by non-disclosers and, indirectly, the seriousness of an HIV diagnosis.

The construction of HIV as dangerous and deadly is not restricted to anonymous online comments. One finds the same kind of framing in the comments of professionals involved in criminalization cases. For instance, during the Aziga trial, the Crown prosecutor referred to HIV as a "slow-acting poison" (Hamilton Spectator 2009). The judge who presided over the Aziga trial, Justice Thomas Lofchik, made several statements over the course of the trial that underscored the seriousness of the offense. In summarizing the evidence, Justice Lofchik stressed for the jury the consequences of Aziga's actions-the fact that two women had died as a result of AIDS-related cancers and that those who were still alive reported having their teeth fall out, sores on their feet that prevented them from walking, and symptoms that persisted despite treatment. At the sentencing hearing at which he was considering the "dangerous offender" designation requested by the prosecution, Justice Lofchik described the consequences of Aziga's actions as "fatal" and said of Aziga that he "represents a gamble on the safety of the women in this community" (CTV News 2011). Similarly, Mark Nagler, a retired sociologist and well-known disability activist who followed the Aziga case closely and was often quoted in the local press, referred to HIV as a "transmissible disability," arguing that:

Society has a right to be protected from its maniacs, no matter where they come from, whether they have intention or not...This is the perspective that the law takes: that society is in need of protection.

[Hemsworth 2005]

A challenge for supporters of criminalization, of course, is how to engage with the argument that opponents make-that while an understanding of HIV as deadly might once have been true, advances in treatment make that view no longer accurate. Many supporters appear to accept that developments in treatment have made a difference. However, they minimize the impact, insisting that while these treatments may have improved life for those living with HIV, they have not changed the fundamental threat that HIV represents. The following comments illustrate this point:

I don't think it's OK to give someone a terrible disease just because the disease isn't as deadly as it used to be. [Positive Living BC 2014] 
The whole "HIV is no longer a death sentence" argument is stupid. You've still been given a life-long incurable disease with potentially bad consequences. [Positive Living BC 2014]

I'm sorry, but I don't want a disease that has no cure, no matter how good the treatments have become, or how long my life *could* be. [Positive Living BC 2014]

Another argument that supporters of criminalization make is that while there have been advances in treatment, not everyone has access to those treatments. They observe that victims of non-disclosers typically come from marginalized groups and groups with lower socio-economic status. These are precisely the individuals, they point out, who have limited access to healthcare and/or may not be able to afford medications. For these individuals, they point out, HIV is just as deadly and devastating as it was 30 years ago. In the same comment feed referred to above, one contributor noted: "If you are poor, it is still a death sentence." Likewise, another contributor, referring to the affordability of medication, stated: "Which means that it's still a death sentence, if you are unemployed or the working poor."

\section{Discussion}

Despite the reconceptualization of HIV as a chronic, manageable infection among most medical professionals, the scientific community, AIDS activists, and people living with HIV understandings of HIV as it was once typified-as a devastating and ultimately deadly virus-persist. The competing views of the disease are evident in the debate around the criminalization of HIV non-disclosure. While those who support criminalization construct HIV as devastating and ultimately terminal, those who oppose criminalization conceptualize HIV as an infection that, with proper management, allows those who are positive to live out normal life spans. The objective of this paper was to uncover and draw attention to these competing views and illustrate how they find expression in the criminalization of non-disclosure debate.

The case study raises several more general issues. First, the case of HIV underlines the extent to which how we view conditions and diseases is affected not only by scientific evidence and interpretations of that evidence but by larger debates within which definitions may become embroiled. In other words, where there are differences in views about disease definitions, those differences may be related to broader social issues. Going back to Brown's (1995) discussion, it may be worthwhile to look at the conditions that fall into the "contested" category and to explore more deeply the social bases for those contestations. Many of the conditions he identifies (e.g., occupational diseases, multiple chemical sensitivity, environmental diseases) are linked to social problems debates about occupational and environmental hazards and risks more generally. It is not unreasonable to suggest that their construction as either legitimate or contested is connected to one's positioning in those debates and that the question of whether they ever get generally recognized as diseases rests, to some extent, on the outcome of those debates. Another example is transability, a condition characterized by a desire on the part of able-bodied individuals to acquire a physical impairment (amputation, paralysis, blindness, etc.). What type of condition transability represents (a psychiatric problem or a dysmorphic disorder like transsexuality) or even whether it is a disease at all and not simply an extreme form of body modification or art (Stevens 2011), are all questions being considered in the context of larger social debates about diver- 
sity and challenges to the notion of "disability" (Lin 2017).

Second, our findings are a good illustration of the socially contingent nature of understandings of HIV specifically, and disease more generally. In that sense, the analysis adds to the literature on the social construction of health and illness. In a social context where individuals have access to the same scientific information about a condition-its manifestations, characteristics, symptoms, treatment options, and prognosis-the case shows that they can, nevertheless, adopt understandings of the condition that are dramatically different and at odds with each other.

Third, the case addresses why definitional contests can emerge in certain instances and provides insight into some of the factors that can potentially generate debate around how a condition ought to be understood. It would be impossible to say how firmly a definition of HIV as chronic and manageable would have taken hold in the absence of the non-disclosure debate. There might well have been a stronger consensus by now that HIV does not represent the threat it once did. But, the fact is that the appropriateness of criminalizing HIV non-disclosure has emerged as an issue and has prompted a debate about the seriousness and nature of the harm perpetrated by non-disclosers. That debate has, in turn, ultimately kept alive the question of how we are to understand the nature of HIV as an infection. The debate around criminalization, and more specifically the claims-making of those who favor a criminal response, are perpetuating a view of HIV (as deadly) that may have otherwise been entirely supplanted by now.

Finally, the case of HIV raises questions about how the construction of problems (diagnostic frames) and solutions (prognostic frames) are linked. One could ask about the criminalization debate whether individuals take a hard line on the criminalization of non-disclosure because they believe HIV is deadly and warrants severe sanctioning; or is it the case that the pursuit of a "get tough" approach to non-disclosure encourages a more dire and fatalistic construction of HIV, and an exaggeration of its impact in discourse about the issue as a way to justify continued criminalization? Conversely, do those who oppose criminalization do so because they really do see HIV as manageable and non-disclosers as benign; or does an anti-criminalization stance encourage as a discursive strategy the construction of HIV in more benign terms and minimization of its potential impact as a way of changing responses to non-disclosure?

Put more generally, the question becomes: do claims-makers seek out certain solutions because of how they understand the problematic condition in question or does the desire to enforce a particular type of solution affect how conditions are constructed? The data in this study do not allow for any definitive conclusions. But the pattern does suggest that more research on the question of the direction of the link between the construction of conditions and solutions would be fruitful. There are certainly cases within the literature that speak to this issue, suggesting that the construction of conditions can, in fact, be solution-driven. One of those cases has been published by Loseke herself (2003b) in a paper on the resolution of the "problem" of homelessness in New York City in the 1980s. Loseke (2003b) discovered that when officials found themselves needing to respond to citizen complaints about the growing presence of the homeless on city streets, they sought to remove them against their will. However, to do so in a way that was legal and not seen as a violation of the rights 
of homeless people, they defined the homeless as mentally ill and used existing involuntary confinement provisions to forcibly remove them. Like the case of HIV discussed in this paper, the study underlines the imperative to consider and analyze more carefully the use of condition constructions as justificatory rhetoric in the pursuit of particular end goals and forms of social control.

\section{References}

Adam, Barry D. 2006. "Infectious Behaviour: Imputing Subjectivity to HIV Transmission." Social Theory and Health 4(2):168179.

Adam, Barry D. 2015. "HIV Disclosure as Practice and Public Policy." Critical Public Health 25(4):386-397.

Adam, Barry D. et al. 2013. "Impacts of Criminalization on The Everyday Lives of People Living with HIV in Canada." Sexuality Research and Social Policy 11(1):39-49.

Alternet.org. 2010. “They're Trying to Call HIV-Positive People Bioterrorists?" Retrieved April 29, 2015 (https://www.alternet. org/2010/04/theyre_trying_to_call_hiv-positive_people_bioterrorists/).

Altheide, David L. and Christopher J. Schneider. 2013. Qualitative Media Analysis. $2^{\text {nd }}$ ed. Thousand Oaks, CA: Sage.

Beaudin, Christy and Susan Chambre. 1996. "HIV/AIDS as a Chronic Disease." American Behavioral Scientist 39(6):684-706.

Bell, Ann. 2016. “The Margins of Medicalization: Diversity and Context Through the Case of Infertility." Social Science \& Medicine 156:39-46.

Berg, Bruce. 2006. Qualitative Research Methods for the Social Sciences. Boston: Allyn and Bacon.

Berger, Peter and Thomas Luckmann. 1967. The Social Construction of Reality. London: Penguin.

Best, Joel. 2015. "Beyond Case Studies: Expanding the Constructionist Framework for Social Problems Research." Qualitative Sociology Review 11(2):18-33.

\section{Acknowledgments}

This paper originated as a chapter in Erica Speakman's doctoral dissertation. The authors are grateful for the feedback provided on that chapter by Roy Cain, James Gillett, and Randy Jackson. The authors also appreciate the thoughtful feedback provided on an earlier draft of this paper by the QSR reviewers.

Bowen, Glenn. 2009. “Document Analysis as a Qualitative Research Method." Qualitative Research Journal 9(2):27-40.

Brown, Phil. 1995. "Naming and Framing: The Social Construction of Diagnosis and Illness." Journal of Health and Social Behavior 35:34-52.

Canadian AIDS Treatment Information Exchange. 2021. A History of HIVIAIDS. Retrieved February 07, 2021 (https://www. catie.ca/en/world-aids-day/history).

Chan, Margaret. 2017. "HIV: From a Devastating Epidemic to a Manageable Chronic Disease." Pp. 36-41 in 10 Years in Public Health 2007-2017. Geneva: World Health Organization.

Clairmont, Susan. 2011. "Choose Your Weapon: Sex as Violence, Love or HIV." Hamilton Spectator, June 29. Retrieved August 13, 2013 (https://www.thespec.com/news/hamilton-region/2011/06/29/choose-your-weapon-sex-as-violence-love-orhiv.html).

Conrad, Peter. 2007. The Medicalization of Society: On the Transformation of the Human Condition into Treatable Disorders. Baltimore, MD: Johns Hopkins Press.

Conrad, Peter and Alison Angell. 2004. "Homosexuality and Remedicalization." Society 41(5):32-39.

Conrad, Peter and Kristin Barker. 2010. "The Social Construction of Illness: Key Insights and Policy Implications." Journal of Health and Social Behaviour 51(Supplement 1):S67-S79.

Conrad, Peter and Joseph W. Schneider. 1992. Deviance and Medicalization: From Badness to Sickness. Philadelphia, PA: Temple University Press. 
CTV News. 2011. "HIV Killer Declared Dangerous Offender." Retrieved November 04, 2016 (https://www.ctvnews.ca/ hiv-killer-declared-dangerous-offender-1.678531).

Elliott, Richard. 1999. Canadian Criminal Law and the Non-Disclosure of HIV Positive Status. Montreal: Canadian HIV/AIDS Legal Network.

Figert, Anne E. 1996. Women and the Ownership of PMS: The Structuring of a Psychiatric Disorder. Hawthorne, NY: Aldine de Gruyter.

Fouchard, Steven. 2014. "HIV-Positive Ottawa Man Acquitted in Nondisclosure Case." Daily Xtra. Retrieved September 22, 2014 (https://xtramagazine.com/power/hiv-positive-ottawa-man-acquitted-in-nondisclosure-case-61288).

Freidson, Eliot. 1970. Profession of Medicine. A Study of the Sociology of Applied Knowledge. Chicago, London: University of Chicago Press.

French, Martin. 2015. “Counselling Anomie: Clashing Governmentalities of HIV Criminalisation and Prevention." Critical Public Health 25(4):427-440.

Galletly, Carol and Steven Pinkerton. 2006. “Conflicting Messages: How Criminal HIV Disclosure Laws Undermine Public Health Efforts to Control the Spread of HIV." AIDS and Behavior 10(5):451-461.

Gamson, Josh. 1989. "Silence, Death, and the Invisible Enemy: AIDS Activism and Social Movement 'Newness."' Social Problems 36(4):351-367.

Gidley, Ben. 2017. "Doing Historical and Documentary Research." Pp. 285-305 in Researching Society and Culture, edited by C. Seale. London: Sage.

Gillett, James. 2011. A Grassroots History of the HIVIAIDS Epidemic in North America. Spokane, WA: Marquette Books LLC.

Globe and Mail. 2010. "AIDS and the Duty Not to Infect." Retrieved August 18, 2013 (https://www.theglobeandmail.com/opinion/editorials/aids-and-the-duty-to-not-infect/article1212498/).

Hacking, Ian. 2000. The Social Construction of What? Cambridge: Harvard University Press.

Hamilton Spectator. 2009. "Killed by a 'Slow Acting Poison.'” Retrieved August 06, 2013 (https://www.thespec.com/news/hamilton-region/2009/04/01/killed-by-a-slow-acting-poison.html).
Harding, Nancy and Colin Palfrey. 1997. The Social Construction of Dementia. London: J. Kingsley.

Hemsworth, Wade. 2005. "HIV Murder Charges Spark Legal, Ethical Debates; AIDS Advocacy Group Worried about ‘Criminalization' of a Medical Condition." Hamilton Spectator, February 26.

Herek, Gregory and Eric Glunt. 1988. “An Epidemic of Stigma: Public Reactions to AIDS." American Psychologist 43(11):886-891.

Hoppe, Trevor. 2014. "From Sickness to Badness: The Criminalization of HIV in Michigan." Social Science \& Medicine 101:139-147.

Horwath, Glennys. 2007. Death and Dying: Sociological Introduction. Cambridge: Polity Press.

Jürgens, Rolf et al. 2009. “Ten Reasons to Oppose the Criminalization of HIV Exposure or Transmission." Reproductive Health Matters 17(34):163-172.

Kling, Rob et al. 1999. “Assessing Anonymous Communication on the Internet: Policy Deliberations." The Information Society 15(2):79-90.

Knight, Rod et al. 2018. “Criminalization of HIV Non-Disclosure: Narratives from Young Men Living in Vancouver, Canada." PLoS One 13(7):e0201110. doi: 10.1371/journal.pone.0201110.

Lazzarini, Zita, Sarah Bray, and Scott Burris. 2002. “Evaluating the Impact of Criminal Laws on HIV Risk Behavior." Journal of Law, Medicine and Ethics 30(2):239-253.

Levine, Martin P. and Richard R. Troiden. 1988. "The Myth of Sexual Compulsivity." Journal of Sex Research 25(3):347-363.

Lichtenstein, Bronwen, Kathryn Whetten, and Casey Rubenstein. 2013. "Notify Your Partners-It's the Law." Journal of the International Association of Providers of AIDS Care (JIAPAC) 13(4):372-378. doi: 10.1177/2325957413494481.

Lin, Kai. 2017. “The Medicalization and Demedicalization of Kink: Shifting Contexts of Sexual Politics." Sexualities 20(3):302-323.

Lincoln, Yvonna S. 1980. Documentary Analysis and Record Utilization: New Uses for Old Methods. Paper Presented as the Annual Meeting of the American Educational Research Association. Boston, MA.

Loseke, Donileen. 2003a. Thinking about Social Problems: An Introduction to Constructionist Perspectives. New Brunswick, NJ: Transaction Publishers. 
Loseke, Donileen. 2003b. "The Homeless Mentally Ill and Involuntary Hospitalization." Pp. 146-153 in Social Problems: Constructionist Readings, edited by J. Best and D. Loseke. New Brunswick, NJ: Transaction Publishers.

McCrea, Frances. 1983. “The Politics of Menopause: The ‘Discovery' of a Deficiency Disease." Social Problems 31(1):111-123.

Merminod, Anne. 2009. "The Deterrence Rationale in the Criminalization of HIV/AIDS." Lex Electronica 3(3):1-34.

Mykhalovskiy, Eric. 2015. "The Public Health Implications of HIV Criminalization: Past, Current, and Future Research Directions." Critical Public Health 25(4):373-385.

Mykhalovskiy, Eric, Jonathan Betteridge, and David McLay. 2010. HIV Non-Disclosure and the Criminal Law: Establishing Policy Options for Ontario. Toronto: Ontario HIV Treatment Network.

Mykhalovskiy, Eric et al. 2016. "“Callous, Cold and Deliberately Duplicitous': Racialization, Immigration and the Representation of HIV Criminalization in Canadian Mainstream Newspapers." Research Report. Retrieved July 26, 2021 (https://ssrn. com/abstract=2874409).

Nguyen, Linda. 2011. “Ontario Man Who Spread HIV to Testify at Hearing." Postmedia News, May 11. Retrieved September 09, 2013 (http://www.nationalpost.com/scripts/Ontario+spread+testify+hearing/4806836/story.html).

Oakley, Ann. 1984. Captured Wombs: A History of Medical Care of Pregnant Women. New York: Basil Blackwell.

O’Byrne, Patrick, Alyssa Bryan, and Marie Roy. 2013. "HIV Criminal Prosecutions and Public Health: An Examination of the Empirical Research." Medical Humanities 39(2):85-90.

Pawluch, Dorothy. 2016. "Health as a Social Construction." Pp. 34-54 in Health and Society: Critical Perspectives, edited by J. Gillett, G. Andrews, and M. Savelli. Toronto: Oxford University Press.

Pawluch, Dorothy. 2019. "On the Unbearable Lightness of Being a Constructionist." American Sociologist 50(2):204-219.

Pfohl, Stephen. 1977. “The 'Discovery' of Child Abuse." Social Problems 24(3):310-323.

Plenty of Fish. 2007. Retrieved September 23, 2014 (http://forums. plentyoffish.com/datingPosts6407166.aspx).
Positive Living BC. 2014. "Canada's Vicious HIV Laws: How the Supreme Court Redefined Safe Sex." Retrieved September 22, 2014 (https://slate.com/technology/2014/05/canada-criminalizes-nondisclosure-of-hiv-status-shifts-responsibility-from-condoms-to-viral-load.html).

Prevention Access Campaign. 2016. "Undetectable = Untransmittable." Retrieved August 02, 2017 (https://www.preventionaccess.org/undetectable).

Queerty. 2010. "Is Canada Really Trying an HIV-Positive Gay Man with Attempted Murder? Yep." Retrieved August 15, 2017 (https://www.queerty.com/is-canada-really-trying-a-hiv-positive-gay-man-with-attempted-murder-yep-20100706).

Samji, Hasina et al. 2013. "Closing the Gap: Increases in Life Expectancy among Treated HIV-Positive Individuals in the United States and Canada." PLoS ONE 8(12):e81355. doi: 10.1371/ journal.pone.0081355.

Scandlyn, Jean. 2000. "When AIDS Became a Chronic Disease." Western Journal of Medicine 172(2):130-133.

Scott, Susie. 2006. “The Medicalisation of Shyness: From Social Misfits to Social Fitness." Sociology of Health and Illness 28(2):133153. doi: 10.1111/j.1467-9566.2006.00485.x.

Scritchfield, Shirley. 2009. "The Construction of Infertility: From Private Matter to Social Concern." Pp. 131-146 in Images of Issues: Typifying Contemporary Social Problems, edited by J. Best. New Brunswick, NJ: Transaction Publishers.

Sobal, Jeffrey and Donna Maurer. 1999. Interpreting Weight. New York: Aldine de Gruyter.

Speakman, Erica. 2017. “Constructing an 'HIV-Killer': HIV Non-Disclosure and the Techniques of Vilification." Deviant Behavior 38(4):392-405.

Spector, Malcolm. 1977. “Legitimizing Homosexuality." Society 14(5):52-56.

Spector, Malcolm and John I. Kitsuse. 1977. Constructing Social Problems. Menlo Park, CA: Cummings Publishing Company.

Stevens, Bethany. 2011. "Interrogating Transability: A Catalyst to View Disability as Body Art." Disability Studies Quarterly 31(4). doi: 10.18061/dsq.v31i4.

Swiffen, Amy. 2015. “Bio-Crime: The Criminalization of HIV in Canada." Law and Governance 17(5):1-6. 
Szasz, Thomas. 1961. "The Uses of Naming and the Origin of the Myth of Mental Illness." American Psychologist 16(2):59-65.

Taylor, Paul. 2011. "Should HIV Non-Disclosure Remain a Crime?" Globe and Mail, December 21. Retrieved August 08, 2013 (https://www.theglobeandmail.com/life/healthand-fitness/should-hiv-non-disclosure-remain-a-crime/article4085873/).

Tight, Malcolm. 2019. Documentary Research in the Social Sciences. Thousand Oaks, CA: Sage.

UNAIDS. 2021. Addressing Inequalities and Getting Back on Track to End AIDS by 2030. Report of the Secretary General. Retrieved July 26, 2021 (https://hlm2021aids.unaids.org/ sg-report/).
Waitzkin, Howard. 1989. "A Critical Theory of Medical Discourse: Ideology, Social Control, and the Processing of Social Context in Medical Encounters." Journal of Health and Social Behavior 30(2):220-239.

Webel, Allison. 2015. "How HIV Became a Treatable, Chronic Disease." The Conversation, December 02. Retrieved July 26, 2021 (https://theconversation.com/how-hiv-became-a-treatablechronic-disease-51238).

World Health Organization. 2021. Global Progress Report on HIV, Viral Hepatitis and Sexually Transmitted Infections. Geneva: WHO. Retrieved July 26, 2021 (https://www.who.int/publications/i/ item/9789240027077).

Zola, Irving. 1972. "Medicine as an Institution of Social Control." Sociological Review 20(4):487-504.

\section{Citation}

Speakman, Erica and Dorothy Pawluch. 2021. “Deadly Disease vs. Chronic Illness: Competing Understandings of HIV in the HIV Non-Disclosure Debate." Qualitative Sociology Review 17(4):24-42. Retrieved Month, Year (http://www.qualitativesociologyreview.org/ENG/archive_eng.php). DOI: https://doi.org/10.18778/1733-8077.17.4.02 